\title{
PROJETO MEU LUGAR
}

\section{SILVA DOS SANTOS, JAKELINE}

Mestra em Arquitetura e Urbanismo pela UFPB. Especialista em Assistência Técnica, Habitação e Direito à Cidade pela UFBA. Professora do Centro Universitário de João Pessoa e do Instituto Superior de Educação da Paraíba. E-mail: jakelinesilvaarquiteta@gmail.com

\section{ROMANO, ELISABETTA}

Doutora em Arquitetura e Urbanismo pela Universidade de São Paulo, Livre docente pela FAU/USP e Professora da Universidade Federal da Paraíba E-mail: Elisabetta.romano@gmail.com

\section{COSTA, FRANCISCO}

Doutor em Arquitetura, Escuela Técnica Superior de Arquitectura de Barcelona e Professor da Universidade Federal da Paraíba. E-mail: xicocosta2001@gmail.com

\section{PROJETO MEU LUGAR: ASSISTÊNCIA TÉCNICA COLETIVA À COMUNIDADE VILA MANGUEIRA}

O projeto foi elaborado por meio de assistência técnica à comunidade Vila Mangueira, na cidade de João Pessoa-PB, no período de fevereiro a outubro de $2014 .{ }^{1} \mathrm{O}$ trabalho foi desenvolvido em parceria com a comunidade; a priori, o objetivo era fazer projetos de melhoria habitacional, tendo em vista que as condições de muitas moradias estavam bem precárias. A própria comunidade inverteu o foco do trabalho e optou por um projeto de melhoria do lugar voltado para um terreno vizinho, vazio e de propriedade pública. Alegaram que seria mais interessante que o projeto trabalhasse uma proposta de espaço público neste local. Dessa forma, o projeto e o processo de assistência técnica a serem desenvolvidos teriam uma abordagem mais coletiva e atenderiam aos moradores como também à população do entorno. Diante desse objetivo, a metodologia definida inseriu a população no processo de projetação. $O$ trabalho desenvolvido traz como contribuição não apenas o resultado do projeto de instalação de equipamentos urbanos na comunidade e a inserção urbana dessa localidade, mas, sobretudo, o processo de elaboração participativa da proposta projetual. O resultado contempla um projeto de intervenção urbana e arquitetônica de um grande espaço público de uso misto, contendo equipamentos de lazer, prática esportiva, mobiliário urbano, uma unidade de Creche Comunitária e uma Unidade de Saúde da Família. 
Figura 1: Localização da comunidade.

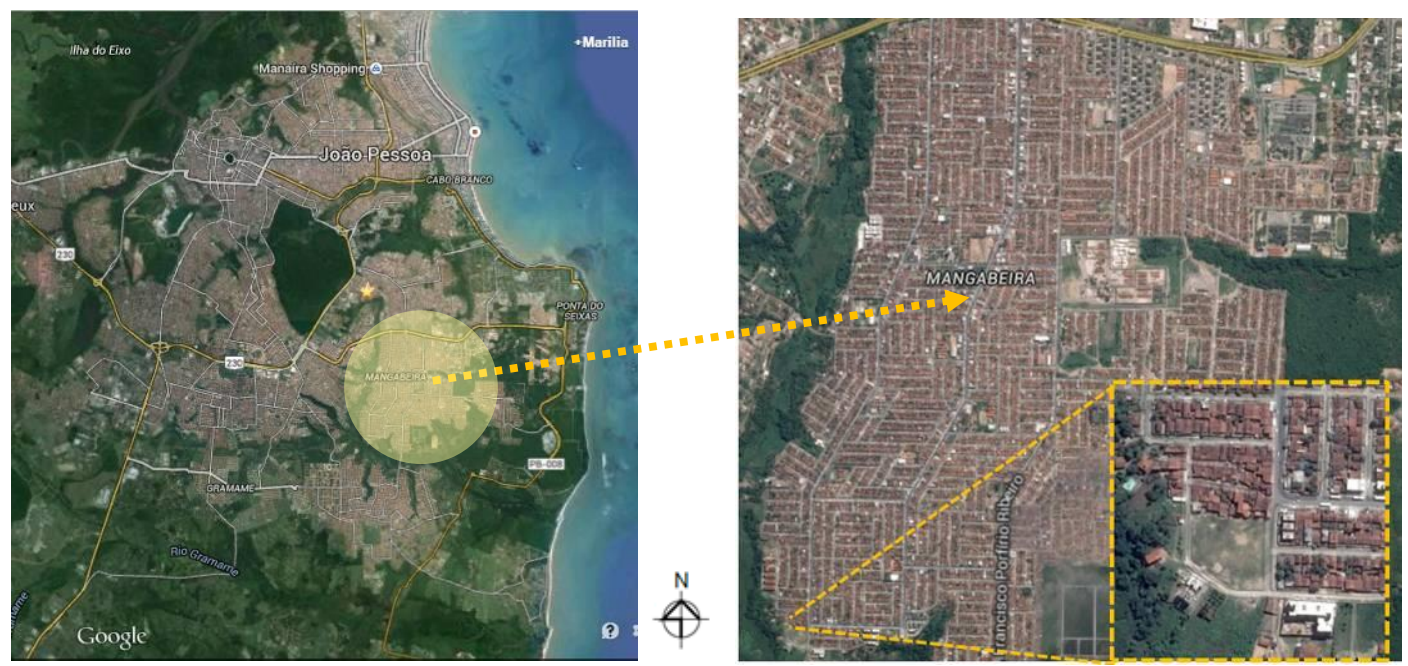

Fonte: Google Maps. Editado pela autora (SANTOS, 2015)

\section{DESENVOLVIMENTO DA PROPOSTA}

O que se propõe com o Projeto Meu lugar, atendendo às demandas colocadas, é incentivar a inserção urbana dessa comunidade, criando um equipamento urbano que permita a interação entre a comunidade e seu entorno, resgatando sua relação com o bairro de Mangabeira. O projeto viabiliza essa interação na disposição dos elementos arquitetônicos e urbanos, adotando a quadra aberta como prerrogativa conceitual. Observadas essas características, propõe-se um equipamento urbano que atenda não só à comunidade imediata, mas também à população do entorno, que registra uma forte carência por equipamentos e espaços públicos, entretanto, com grande ocupação habitacional.

O cadastro socioeconômico e oficinas realizadas então identificaram as problemáticas e potencialidades da Vila Mangueira e do bairro de Mangabeira. A proposta foi elaborada com o auxílio de metodologias participativas, apoiando-se em oficinas de desenho para crianças e adultos e confecção de maquete física para auxiliar na distribuição dos equipamentos propostos pelos moradores.

Figura 2: Demonstrativo de demandas da comunidade.

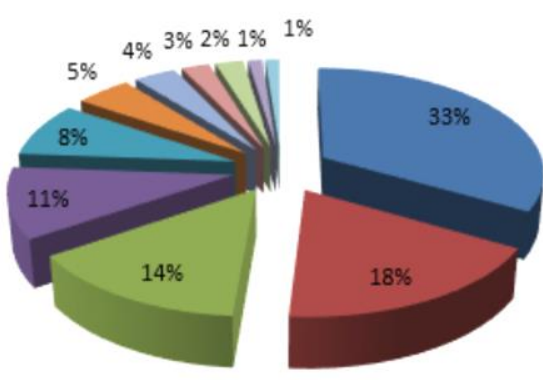

$$
\begin{aligned}
& \text { = Praça } \\
& \text { = Infraestrutura } \\
& \text { = Policiamento } \\
& \text { = Posto de Saúde } \\
& \text { = Creche/Berçario } \\
& \text { = Escola } \\
& =\text { Transporte } \\
& \text { - Mercado } \\
& =\text { Campo de Futebol } \\
& \text { = Moradia }
\end{aligned}
$$

Fonte: Acervo do projeto (SANTOS, 2015).

A partir da definição de demandas se iniciou a fase de projetação. O grande desafio desta empreitada foi elaborar um projeto de assistência técnica coletiva capaz de abrigar os anseios da comunidade, as questões técnicas e construtivas e a viabilidade econômico-financeira. Para tanto, partiu-se do seguinte método: Elaboração de oficinas temáticas, envolvendo a comunidade diretamente na tomada de decisões e no processo projetual, ocorridas na Casinha, local cedido pela ONG-CESAC, atuante nessa comunidade. Essa decisão de projetação conjunta nem sempre é usual em projetos de assistência técnica, que postulam ser necessário manter a participação da população até a fase de demandas, sem envolvê-la na etapa de projeto, sendo essa uma fase mais técnica do processo. Felizmente, decidimos seguir com a metodologia participativa de forma integral, o que contribuiu para um resultado de grande aprendizagem mútua. É importante destacar que a participação na elaboração do projeto empodera a comunidade e fortalece os laços de pertencimento 
no bairro, resultando em trabalhos mais ricos com relação ao contexto no qual se insere. Seguindo esses preceitos, realizou-se a primeira oficina com a participação dos adultos, intitulada "Planejando meu Bairro". Para que todos pudessem participar do processo, utilizou-se o recurso da maquete como instrumento de projetação. A imagem aérea da ocupação da comunidade, com o terreno anexo, foi colocada sobre uma base, enquanto os equipamentos propostos nas demandas, se transformaram em pequenos blocos a serem colocados nessa base. Com base nesta dinâmica, a equipe técnica fez suas intervenções, apontando questões como insolação, ventilação, topografia e racionalidade construtiva, buscando estabelecer uma conexão entre o conhecimento empírico dos moradores com o conhecimento técnico da equipe.

Figura 3: Oficina Planejando meu bairro.

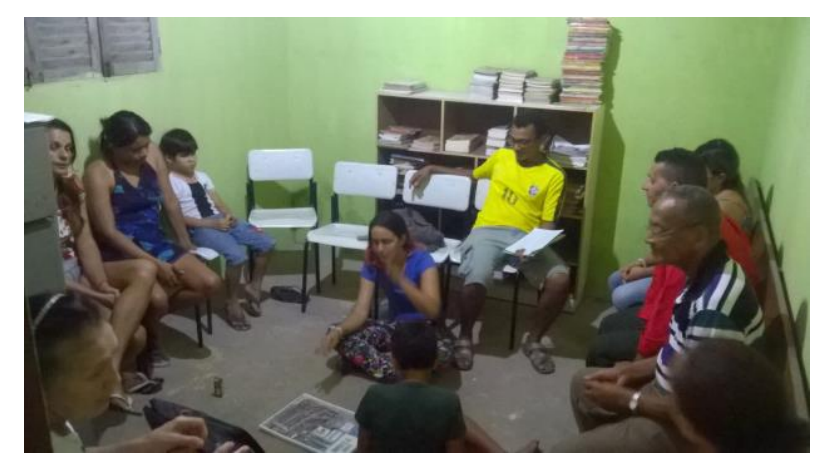

Fonte: Acervo do projeto (SANTOS, 2015).

Figura 4: Maquete esquemática de implantação. Produzida pelos moradores.

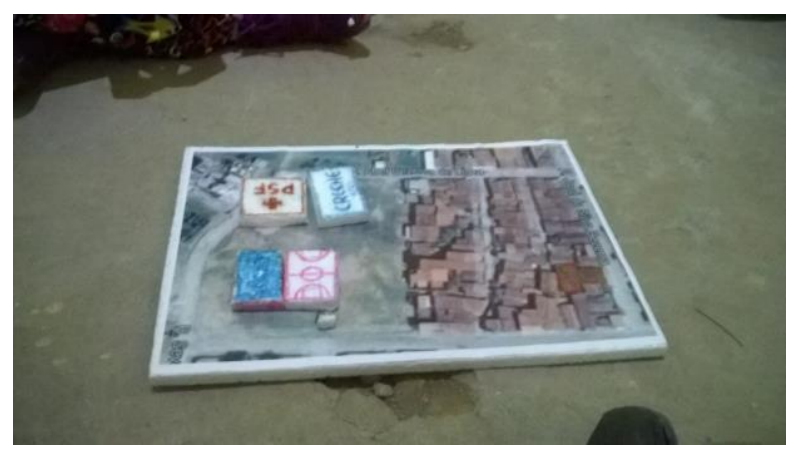

Fonte: Acervo do projeto (SANTOS, 2015).

A segunda oficina, denominada "Eu queria que fosse assim", foi realizada com as crianças da comunidade. O método utilizado baseou-se no desenho livre, sendo solicitado que as crianças desenhassem um mapa mental do terreno, demonstrando os desejos de cada uma para a área de intervenção. O entrosamento e expressividade das crianças ajudaram bastante nesse processo.

Figura 5: Oficina "Eu queria que fosse assim"

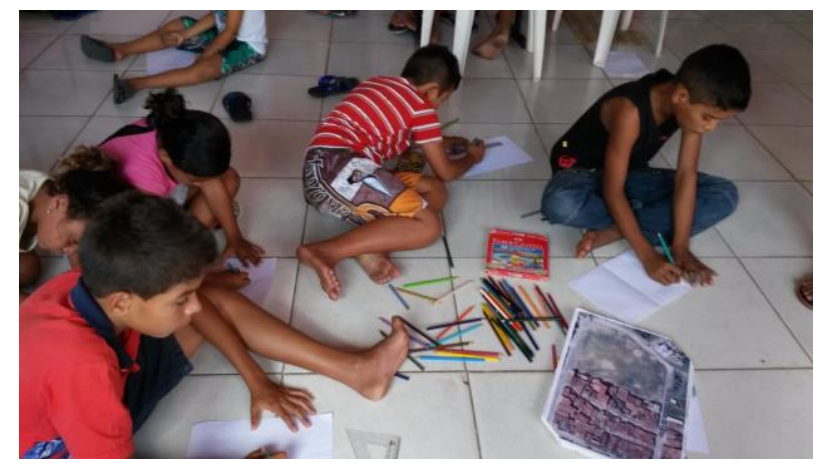

Fonte: Acervo do projeto (SANTOS, 2015). 
Com a finalização das oficinas e a definição dos primeiros esboços de implantação das propostas, passou-se então a elaboração do projeto. A Residência em Arquitetura Urbanismo e Engenharia, da Universidade Federal da Bahia, curso de especialização que viabilizou este projeto, tem por base o conceito de multiplicação, possibilitando que as boas práticas de projeto possam ser replicadas e readaptadas para novas situações e realidades. Com essa inspiração, gerou-se o partido arquitetônico e urbanístico do projeto a seguir.

A proposta destaca, na trama organizacional do projeto, o desenho formado pela repetição de ondas que se propagam, a partir de um ponto central, seguindo suas diretrizes de multiplicação. Na figura abaixo é possível verificar que a paginação do piso se expande, articulando os espaços cheios e vazios, sugerindo linhas de setorização das funções e da localização dos equipamentos. Este foi o partido adotado para desenvolver a proposta.

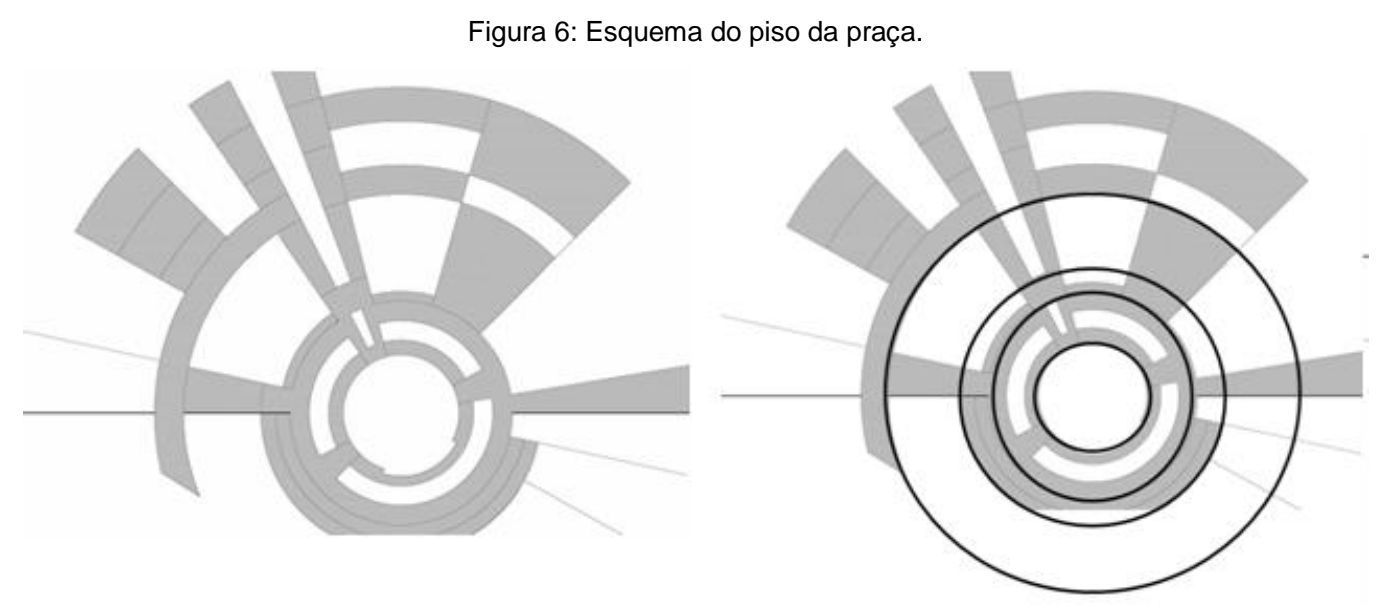

Fonte: Acervo do projeto (SANTOS, 2015).

Os acessos de pedestres, definidos pela paginação de piso, formam a continuidade dos principais percursos das áreas esportivas e se revelam como definidores da relação entre os espaços cobertos, formados pelos blocos da Creche Comunitária e da Unidade de Saúde da Família - USF, e os espaços descobertos, formados pelas áreas de lazer e de convívio, tornando a praça um contínuo de cheios e vazios.

As definições mais complexas na concepção do projeto tratavam da Creche Comunitária e da Unidade de Saúde da Família. Esse tipo de equipamento exige uma série de prerrogativas, inclusive as creches contam com tipos e modelos disponibilizados pelo FNDE- Fundo Nacional de Desenvolvimento da Escola, de forma a nortear sua construção nos municípios. Para tanto levou-se em consideração os programas de necessidades e distribuição de espaços semelhantes a outras edificações de mesma função construídos pela Prefeitura Municipal de João Pessoa-PMJP. Sob essa consideração, foram modificadas apenas a implantação e a modulação adotando características próprias ao projeto em análise. Nessa mesma lógica, para a USF, adaptaram-se os ambientes propostos aos projetos da PMJP, com uma estrutura e implantação compatíveis com o projeto da praça. Especificamente para a Creche, foi adotado como modelo o tipo C, estabelecido pelo FNDE, onde são respeitados os zoneamentos propostos e readaptado o modelo de distribuição em planta-baixa. Esses fatores determinam a viabilidade construtiva e principalmente financeira, pois é notório que esses equipamentos contam com destinação de verba federal para sua construção, com exigências especificas. Os dois equipamentos, a Creche Comunitária e a Unidade de Saúde da Família, apesar de terem usos distintos, são abrigados embaixo de uma única cobertura, decorrendo disso a criação de um pátio interno entre os dois principais blocos construídos. A cobertura única, sustentada por perfis metálicos, com telha ecológica, é economicamente viável e rápida de ser construída. Assemelha-se às estruturas utilizadas para coberturas de pavilhões e mercados. A estrutura proposta permite que toda a construção esteja livre, o que possibilita um alto fluxo de ventilação e iluminação naturais, diminuindo a utilização de aparelhos de ar condicionado e de luz artificial. 
Figura 7: Vista do Bloco da Creche Comunitária e Unidade de Saúde da Família.

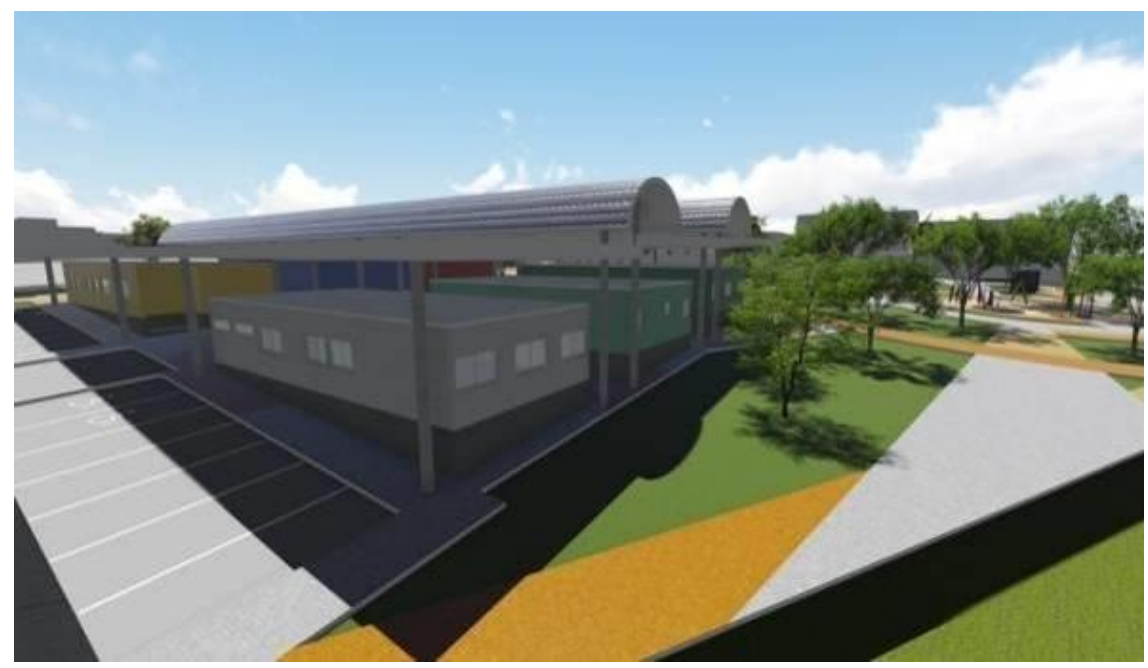

Fonte: Acervo do projeto (SANTOS, 2015).

No projeto Meu Lugar, há preocupação com a exequibilidade projetual e a busca por soluções integradas das áreas de convívio e dos equipamentos físicos, a exemplo da manutenção da vegetação, que conta com a captação de águas da chuva pela cobertura metálica da Creche e USF. Para o posto de apoio policial, foi proposta a utilização de um container, como já utilizado pela PMJP, para pontos de apoio da guarda Municipal, distribuídos em vários pontos da cidade. O container é economicamente viável, cumpre seu papel de ponto de apoio, e pode ser transferido de lugar sem grandes dificuldades. É importante destacar que o projeto de intervenção urbana e arquitetônica aqui apresentado é, do ponto de vista construtivo, viável economicamente. O sistema estrutural proposto pode ser constituído por componentes modulares metálicos pré-fabricados, coberto com telha ecológica de material reciclado e, portanto, não poluente. O sistema construtivo prevê o uso de alvenaria estrutural, modelo de construção mais presente no mercado da construção paraibana. Esse tipo de construção tem facilidade de execução, podendo inclusive absorver a mão de obra local com histórico de trabalhos na construção civil.

Figura 8: Vista da implantação geral- projeto Meu Lugar.

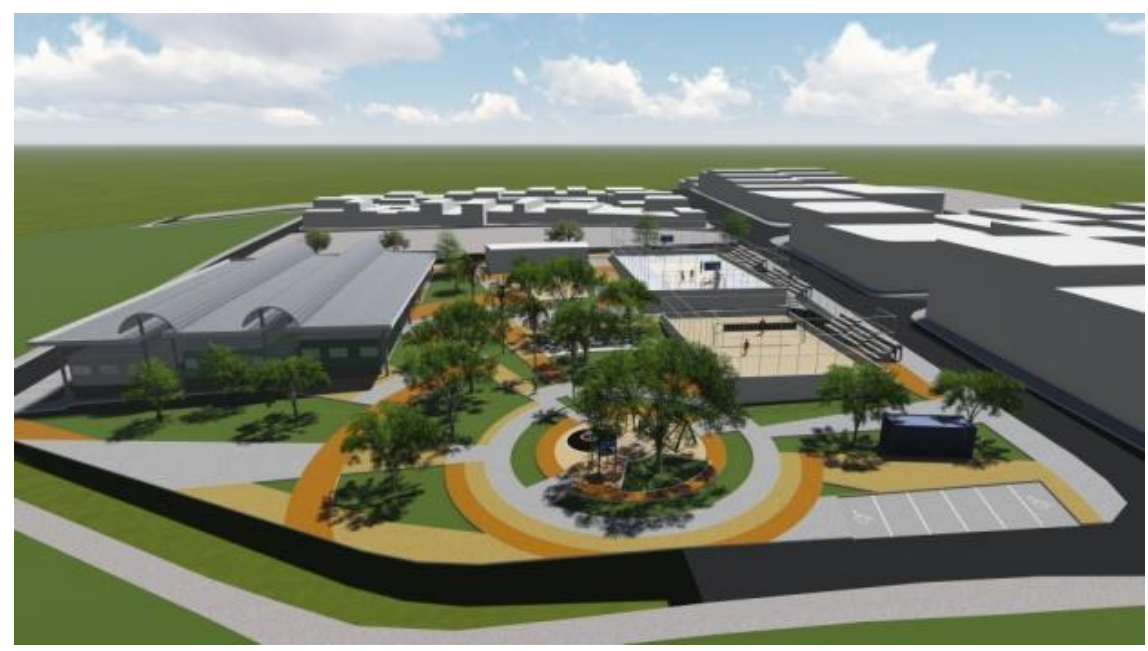

Fonte: Acervo do projeto (SANTOS, 2015).

A praça também é equipada com grande diversidade de árvores nativas, canteiros e playgrounds. As calhas podem coletar e direcionar por gravidade a água captada, que deverá ser reutilizada na irrigação dos gramados e dos canteiros, como também na lavagem das áreas externas da praça. A existência de espaços livres é uma prerrogativa do projeto, devendo ser preservada, evitando que, no futuro, a construção de novos equipamentos possa vir a descaracterizá-la. O projeto é implantado em terreno público, não havendo, portanto, necessidade de ações de desapropriação por subutilização da terra urbana; no entanto, é necessário resgatar o enorme potencial que a área apresenta. Nesse sentido, é preciso dispor dos instrumentos urbanísticos previstos no Estatuto da Cidade como operações urbanas e outorga onerosa que geram recursos 
para serem investidos nas áreas mais frágeis da cidade. Essa proposta preliminar viabiliza 0 dimensionamento para a busca por recursos financeiros para os investimentos públicos e patrocínios junto à iniciativa privada, para sua implantação. Recomenda-se que as áreas de comércio proposta sejam utilizadas como fonte de renda, preferentemente pelos moradores da comunidade. Outras recomendações e diretrizes de detalhamento, dimensões e usos, devem constar nas especificações do projeto executivo, na medida em que essa proposta tenha prosseguimento.

Figura 9: Vista da paginação de piso e áreas verdes.

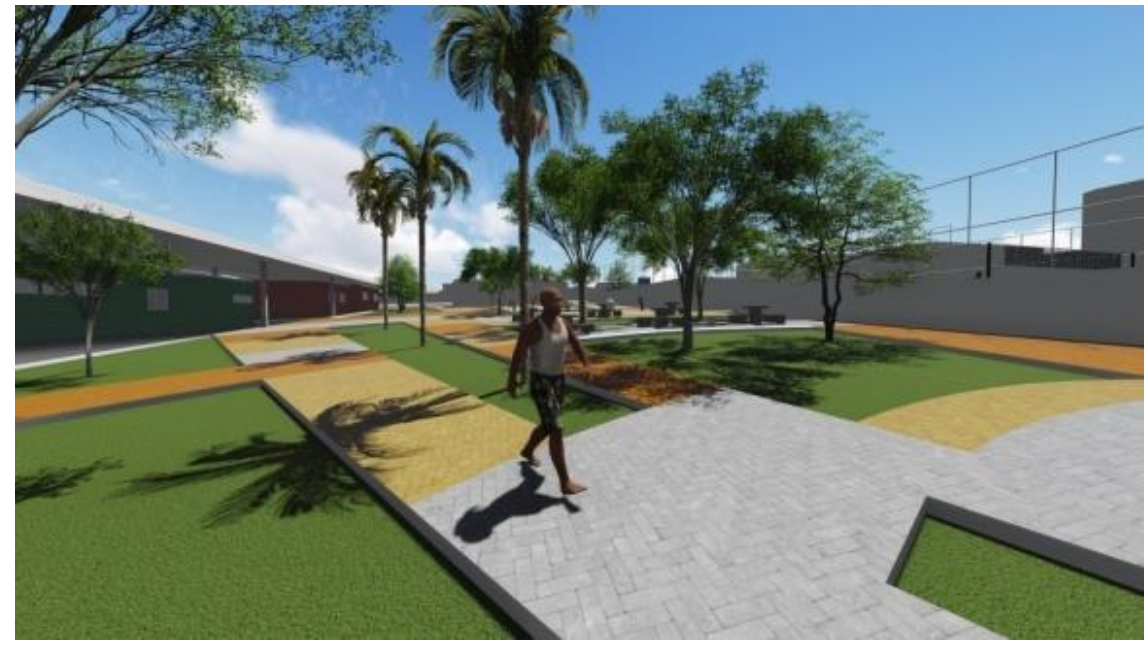

Fonte: Acervo do projeto (SANTOS, 2015).

As ações de assistência técnica são definidas pela Lei 11.888/2008 - Lei da Assistência Técnica Pública e Gratuita. Esta lei determina que a assessoria técnica pode ser de forma coletiva, direcionada para associações ou grupos de moradores. Levando em consideração a referida lei, o projeto Meu Lugar se insere dentro do que reza a legislação e implementou a assistência técnica coletiva, mediada pela ONG CESAC, à comunidade Vila Mangueira. A prestação deste serviço pode ser mais amplamente efetivada com o apoio financeiro da União, do Estado e do Município, através de convênios de cooperação. Ainda através da ONG CESAC, o projeto poderá se habilitar no Orçamento Participativo da cidade de João Pessoa, sendo essa, também, uma forma de viabilizar este projeto. Vale ressaltar que João Pessoa possui legislação própria que trata sobre arquitetura e engenharia públicas (Lei 10.984/2007), o que fortalece o embasamento legal desta proposta de intervenção.

\section{CONSIDERAÇÕES FINAIS}

No processo aqui descrito, o mais importante a destacar é o método participativo adotado. Nesse contexto que aborda processo e produto, essa metodologia viabilizou a troca de saberes entre a equipe técnica e os moradores. A proposta conseguiu, portanto, contemplar as demandas identificadas, colocando as ações da assistência técnica não como assistencialismo, mas como prática e técnica de melhoria urbana, alcançando, desta forma, resultados passíveis de serem multiplicados em outras ações e projetos de intervenção em contextos similares, em outras cidades brasileiras. Dentro desta ótica, o curso de especialização em tela que viabilizou a elaboração de tal projeto, capacitando profissionais em prática participativa com a comunidade, traz de fato um potencial multiplicador, como uma das formas de efetivação e regulamentação da aplicação da Lei Federal 11.888/2008 de Assistência Técnica Pública e Gratuita, evitando, assim, que essa lei tão necessária para a construção das cidades brasileiras venha a se tornar uma "letra morta".

O referido projeto, ao final, foi apresentado à comunidade em março 2015. Naquela oportunidade os moradores puderam ver a materialização do trabalho desenvolvido por todos os participantes. Com a mediação da ONG-CESAC, o projeto foi apresentado à Comissão do Orçamento Participativo da cidade e à Secretaria Municipal de Planejamento nesse mesmo ano, quando foram constatadas a viabilidade e a pertinência da proposta. Ainda em 2015, o referido projeto foi selecionado para integrar a Mostra Paraibana de Arquitetura na categoria Cidades, realizada pelo IAB-PB. As repercussões em âmbito local demonstram a relevância da proposta e certamente valorizam futuras ações de assistência técnica, fortalecendo a profissão do arquiteto urbanista em prol do direito à cidade. 


\section{REFERÊNCIAS}

BRASIL. Lei no 11.888, de 24 de Dezembro de 2008, Assegura às famílias de baixa renda Assistência Técnica Pública e Gratuita para o projeto e a construção de habitação de interesse social e altera a Lei no 11.124, de 16 de junho de 2005. Brasília, 24 de dezembro de 2008. Disponível em www.planalto.gov.br/Ccivil_03/leis. Acesso em maio de 2015.

CUNHA, E. M. P; ARRUDA, A. M. V; MEDEIROS, Y. (Org.). Experiências em Habitação de Interesse Social no Brasil. Brasília: Ministério das Cidades, Secretaria Nacional de Habitação, 2007.

GORDILHO-SOUZA, A. Assistência Técnica em Arquitetura, Urbanismo e engenharia: Avanços Institucionais. In: 6ำ Projetar - O Projeto como Instrumento para a Materialização da Arquitetura: ensino, pesquisa e prática. Anais. SalvadorBA, Brasil, 2013.

GIANNELLA, V; MOURA,M.S. Gestão em Metodologias Não Convencionais para a Gestão Social. Roteiros Gestão Social, Salvador: Série editorial CIAGS, 2009.

LIMA, E. T; MORAES, A. (Org.). Manual de Metodologias Participativas Para o Desenvolvimento Comunitário. Brasíl/Canadá, s/ data.

SANTOS, J, S. Assistência Técnica Pública e Gratuita: Um estudo de implantação para municípios paraibanos. Dissertação de Mestrado PPGAU/UFPB, Paraíba,2014.

SANTOS, J. S, Projeto Meu Lugar: Assistência Técnica Coletiva a Comunidade Vila Mangueira- João Pessoa/Pb. Trabalho Final do Curso de Especialização Assistência Técnica, Habitação e Direito à Cidade. Salvador, PPGAU-UFBA, jan.2015.

SECRETARIA MUNICIPAL DE HABITAÇÃO SOCIAL - SEMHAB; PREFEITURA MUNICIPAL DE JOÃO PESSOA. Termo de referência para contratação de serviços de Assistência Técnica individual na comunidade Mussumago e adjacências. Paraíba, p. 3-14, 2012.

\section{NOTAS}

${ }^{1}$ Este texto tem como base o Trabalho Final apresentado pela autora, com mesmo título, na conclusão do Curso de Especialização Assistência Técnica, Habitação e Direito a Cidade, na modalidade Residência Profissional em Arquitetura, Urbanismo e Engenharia, da Universidade Federal da Bahia, tendo como tutores os Profs. Drs. da UFPB Elisabetta Romano e Francisco Costa, em cooperação com a UFBA. Para um maior detalhamento, ver SANTOS, 2015.

NOTA DO EDITOR (*) O conteúdo do artigo e as imagens nele publicadas são de responsabilidade do(s) autor(es). 